\title{
Trends in equity of inpatient health service utilization for the middle-aged and elderly in China: based on longitudinal data from 2011 to 2018
}

\author{
Xiaojing Fan ${ }^{1}$, Min Su ${ }^{2 *}$, Yaxin Zhao ${ }^{3}$, Yafei $\mathrm{Si}^{4}$ and Zhongliang Zhou ${ }^{1}$
}

\begin{abstract}
Background: The aim of this study was to assess the trends in equity of receiving inpatient health service utilization (IHSU) in China over the period 2011-2018.

Methods: Longitudinal data obtained from China Health and Retirement Longitudinal Studies were used to determine trends in receiving IHSU. Concentration curves, concentration indices, and horizontal inequity indices were applied to evaluate the trends in equity of IHSU.

Results: This study showed that the annual rate of IHSU gradually increased from 7.99\% in 2011 to $18.63 \%$ in 2018. Logistic regression shows that the rates of annual IHSU in 2018 were nearly 3 times (OR $=2.86,95 \% \mathrm{CL}: 2.57,3.19)$ higher for rural respondents and 2.5 times $(\mathrm{OR}=2.49,95 \% \mathrm{CL}: 1.99,3.11)$ higher for urban respondents than the rates in 2011 after adjusting for other variables. Concentration curves both in urban and rural respondents lay above the line of equality from 2011 to 2018. The concentration index remained negative and increased significantly from -0.0147 ( $95 \% \mathrm{CL}:-0.0506,0.0211)$ to -0.0676 (95\% CL: $-0.0894,-0.458)$, the adjusted concentration index kept the same tendency. The horizontal inequity index was positive in 2011 but became negative from 2013 to 2018, evidencing a pro-low-economic inequity trend.

Conclusions: We find that the inequity of IHSU for the middle-aged and elderly increased over the past 10 years, becoming more focused on the lower-economic population. Economic status, lifestyle factors were the main contributors to the pro-low-economic inequity. Health policies to allocate resources and services are needed to satisfy the needs of the middle-aged and elderly.
\end{abstract}

Keywords: Inpatient health service utilization, Equity, Middle-aged and elderly

\section{Background}

Equity in health service utilization, as a significant outcome of health systems, has always attracted extensive research interest [1-8]. Health services should be equitably distributed, whereby people who have greater need should use health services proportionally more than

\footnotetext{
* Correspondence: sumin1227@126.com

${ }^{2}$ School of Public Administration, Inner Mongolia University, Hohhot, China Full list of author information is available at the end of the article
}

those with less need [9]. However, studies have shown that there were differences in health service utilization, even with the same need, whereby individuals with higher economic status, greater education, and health insurance utilize more health services $[2,3,10]$.

As a rapidly industrializing middle-income country, the widening income-related inequity in access to health services among residents has been a growing concern of the Chinese government. In response to the growing

(C) The Author(s). 2021 Open Access This article is licensed under a Creative Commons Attribution 4.0 International License, which permits use, sharing, adaptation, distribution and reproduction in any medium or format, as long as you give appropriate credit to the original author(s) and the source, provide a link to the Creative Commons licence, and indicate if changes were made. The images or other third party material in this article are included in the article's Creative Commons licence, unless indicated otherwise in a credit line to the material. If material is not included in the article's Creative Commons licence and your intended use is not permitted by statutory regulation or exceeds the permitted use, you will need to obtain permission directly from the copyright holder. To view a copy of this licence, visit http://creativecommons.org/licenses/by/4.0/. The Creative Commons Public Domain Dedication waiver (http://creativecommons.org/publicdomain/zero/1.0/) applies to the data made available in this article, unless otherwise stated in a credit line to the data. 
inequalities in healthcare utilization, the Chinese government has made substantial effort since 2002 to reduce the burden of inpatient costs and make healthcare more affordable for patients. In 2009, the Chinese government launched a new healthcare reform policy with the goal of effectively reducing the burden of medical expenses and providing affordable universal healthcare for all citizens [11-15]. In 2011, the Chinese government set a target to reimburse approximately $70 \%$ of inpatient expenses. In 2013, the National Health Commission increased the rate of reimbursement expense for inpatient health service to around $75 \%$ for rural residents. These health policies that favor people at lower income levels have made significant progress in the provision of health services in recent decades by treating affordability as a major barrier to equal access to health services. For the middle-aged and elderly, we also assume that their inpatient health service utilization (IHSU) is gradually increasing recently. However, although the inequality in the utilization of health services among middle-aged and elderly still exists and has formed a relatively serious social problem, there are relatively few studies on the latest trends in their IHSU. Middle-aged and elderly population bear a higher burden of chronic diseases, depression, disability and other diseases than young people as they grow older, which leads to a greater demand for medical services, especially inpatient care, it is essential to monitor the changes in IHSU rates.

Previous studies in China have provided a rich foundation for the study of IHSU. Zhu et al. analyzed both regional and individual socioeconomic factors associated with the inequality of outpatient and inpatient service utilization in China, using data from 1991 to 2011, and they provided evidence to improve governmental health policies [2]. Some scholars have suggested that inequality should be reduced by reducing the income gap between the rich and the poor through social risk protection after a study on the equity of IHSU in rural areas of China [3]. Some scholars have also studied the equity of IHSU among the elderly and found that there is an inequality that tends to be higher-economic groups, while the New Rural Cooperative Medical Scheme is less effective in reducing this inequality [16]. In addition, the National Health Service survey of China has showed a gradually enhancing trend in IHSU rate (from $6.8 \%$ in 2008 to $9.0 \%$ in 2013) for the all-age population [17, 18]. Our study aims to update the information on the trends in annual rates and equity of IHSU among an older segment of the population-the middle-aged and elderly, to quantify personal socioeconomic factors associated with inequalities in IHSU in China, and to provide scientific evidence and recommendations for improving governmental health policies concerning healthcare inequity.

\section{Methods \\ Data}

Data were drawn from the 2011, 2013, 2015, and 2018

China Health and Retirement Longitudinal Studies (CHARLS), which used a structured questionnaire with a longitudinal large-scale nationally representative sample of people aged 45 years or older (the data and questionnaire are available at http://charls.pku.edu.cn/) [19]. Employing four-stage stratified sampling, CHARLS was implemented in 2011 to cover 28 provinces in China and investigated a sample of 17,708 participants in about 10,257 households in 150 counties/districts [20]. The baseline data collection was performed in 2011 with an overall response rate of $80.5 \%$, and then three follow-up interviews were conducted in 2013, 2015 and 2018. In the study, 11,912 re-contacted respondents were enrolled. The detailed process is shown in Fig. 1.

\section{Measures}

CHARLS baseline data included detailed information of respondents and their living spouses. The main questionnaire included information on basic demographics, family, health status, healthcare and health insurance, and household and individual economy. The "healthcare and health insurance" section in the questionnaire provided the most important information for this study. The outcome variable, IHSU, was based on respondents' reports from the 2011-2018 waves on the following item: "Have you received inpatient care in the past year?" This was a binary variable, whereby 0 denoted "no" and 1 denoted "yes". The key independent variables included respondents' gender, age, education, insurance, income, living status, sleeping hours, smoking status, alcohol consumption, and health status taken from the 2011 wave of CHARLS. Living place was divided into rural and urban groups. Respondents' education was coded into two levels: (1) lower than elementary school, and (2) high school and above. Household income per capita was a continuous variable, calculated as the sum of personal assets, household assets, personal income and income from other household members, household income from agriculture, household income from selfemployment, and household income from transfers divided by the total number of family members in the household. It was further divided into three groups. In order to make inference to the whole population in China, we considered individual weight with household and individual non-response adjustment at baseline, the adjusted data were included in the CHARLS data.

Considering the fact that there are huge socioeconomic gaps between rural and urban areas in China, rural residents are more likely to encounter barriers (inadequate healthcare insurance coverage, long distances to healthcare facilities, lack of transportation, and an 


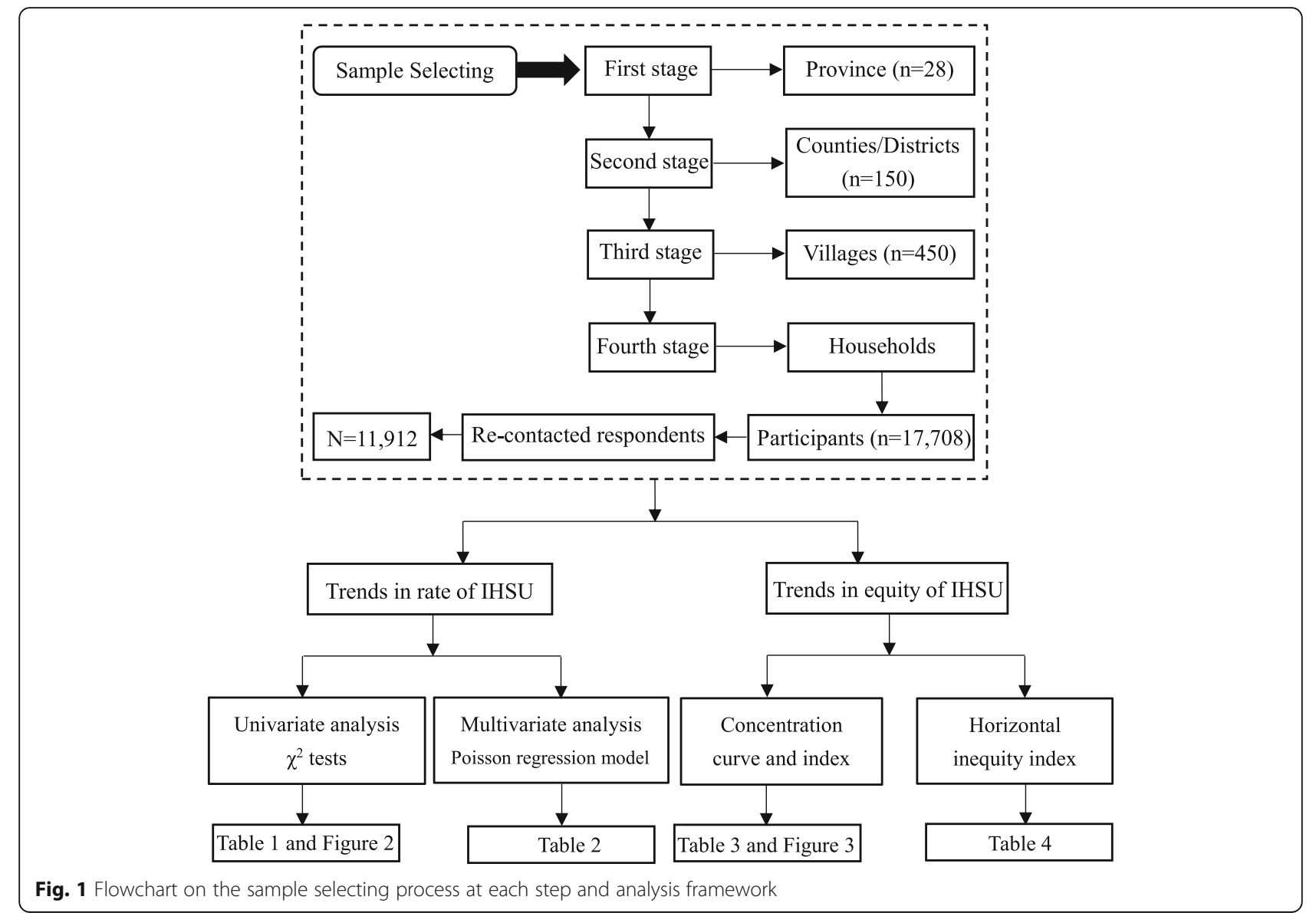

undersupply of particular specialists) to receiving health services than people in urban areas [2, 21-24]. Accordingly, the rural and urban samples were analyzed separately.

\section{Health inequity}

Concentration curves, concentration indices, and their decomposition were applied to analyze the equity of IHSU. Concentration curves and indices were used to measure the extent of economic status-related inequality in the distribution of IHSU across the population [25, 26]. A positive concentration index denotes that people with high economic status use more IHSU than their low-economic counterparts, whereas a negative index denotes the opposite. The $\mathrm{CI}$ formula was as follows:

$$
C=\frac{2}{\mu} \operatorname{COV}(y, \gamma)
$$

where $\mathrm{C}$ is defined in terms of the covariance between the outcome variable $(\mathrm{y})$ and the fractional ranks of household income $(\gamma) ; \mu$ is the mean of $y$. The outcome variable IHSU in this study is a binary variable, Wagstaff proposed a method for correcting CI [26], the formula as follows:

$$
\mathrm{C}_{\text {adjusted }}=\frac{1}{1-\mu} C
$$

Inequality can be further explained by decomposing the concentration index into its determining components; then, the horizontal inequity index (HI) can be computed by subtracting the contribution of variables (such as sex, age, health status) from the concentration index of IHSU [9]. These determinants were selected according to previous research, constrained by the variables collected in the investigation [27, 28]. A probit regression model was used to indirectly standardize the IHSU since the outcome variable was binary.

\section{Analytical strategy}

Categorical variables were presented as absolute numbers as a proportion of the total number of participants. Chi-square tests were used to separately test whether the rates of IHSU were statistically significant for the rural and urban samples. Logistic regression was employed to analyze the adjusted odds ratios (ORs) for 
IHSU after controlling for a number of confounding factors at baseline, such as the year $(2011,2013,2015$, and 2018), sex, age, education, insurance, household income per capita, living status, sleeping hours, smoking and drinking status, and having a disability and chronic disease.

All statistical analyses were performed using STATA statistical software version 14.0 (StataCorp LP, College station 77,845 , USA). A two-tailed $p$-value $<0.05$ was considered statistically significant.

\section{Results}

\section{Descriptive statistics}

According to the descriptive statistics in Table 1, 46.28\% of the middle-aged and elderly were male and 53.72\% were female. For rural respondents, $64.25 \%$ of them were aged between 45 and 60 years, while this age range constituted $57.60 \%$ of the urban cohort. More rural respondents were educated below elementary-school level (74.50\%), while more urban respondents were educated above middle-school level (62.07\%). Furthermore, $92.80 \%$ of rural respondents and $84.04 \%$ of urban respondents had insurance. The majority of respondents in all groups were living with others, sleeping more than $7 \mathrm{~h}$, and not smoking and drinking. Only $17.79 \%$ of the rural middle-aged and elderly had a disability, whereas $33.14 \%$ of them had a chronic disease; on the other hand, $12.79 \%$ of the urban middle-aged and elderly had a disability, whereas $33.14 \%$ of them had a chronic disease.

\section{Tendency of rate of IHSU}

Figure 2 presents the rate of annual IHSU from 2011 to 2018. In total, the proportion of urban respondents

Table 1 Basic characteristics of respondents in $2011(n=11,912)$

\begin{tabular}{|c|c|c|c|c|}
\hline Variables & Group & Rural $(n=9808)$ & Urban $(n=2092)$ & $P$ \\
\hline \multicolumn{5}{|l|}{ Demographics } \\
\hline \multirow[t]{2}{*}{ Sex } & Male & $4423(45.13)$ & $1081(51.67)$ & $<0.001$ \\
\hline & Female & $5377(54.86)$ & $1011(48.33)$ & \\
\hline \multirow[t]{4}{*}{ Age (years) } & $45-50$ & $2477(25.25)$ & $443(21.18)$ & $<0.001$ \\
\hline & $51-60$ & $3825(39.00)$ & $760(36.32)$ & \\
\hline & $61-70$ & $2531(25.81)$ & $615(29.40)$ & \\
\hline & $\geq 71$ & $975(9.95)$ & 274(13.10) & \\
\hline \multirow[t]{2}{*}{ Education } & sElementary school & $7302(74.50)$ & 792(37.93) & $<0.001$ \\
\hline & $\geq$ Middle school & $2499(25.50)$ & $1296(62.07)$ & \\
\hline \multirow[t]{2}{*}{ Insurance } & No & $702(7.20)$ & $330(15.96)$ & $<0.001$ \\
\hline & Yes & $9045(92.80)$ & 1738(84.04) & \\
\hline \multirow[t]{3}{*}{ Household income per capita (CNY) } & Low & $2595(27.11)$ & $297(14.86)$ & $<0.001$ \\
\hline & Medium & $5072(52.98)$ & $714(35.72)$ & \\
\hline & High & 1906(19.91) & $988(49.42)$ & \\
\hline \multicolumn{5}{|l|}{ Life style } \\
\hline \multirow[t]{2}{*}{ Living status } & Live with others & $8122(82.81)$ & 1819(86.95) & $<0.001$ \\
\hline & Live alone & 1686(17.19) & $273(13.05)$ & \\
\hline \multirow[t]{3}{*}{ Sleeping hours } & $7-8 \mathrm{~h}$ & 3762(38.36) & $883(42.21)$ & $<0.001$ \\
\hline & $\leq 6 \mathrm{~h}$ & $4576(46.66)$ & $980(46.85)$ & \\
\hline & $>8 \mathrm{~h}$ & $1470(14.98)$ & $229(10.95)$ & \\
\hline \multirow[t]{2}{*}{ Smoking status } & Yes & $3768(38.53)$ & 787(37.84) & 0.554 \\
\hline & No & $6011(61.47)$ & $1293(62.16)$ & \\
\hline \multirow[t]{2}{*}{ Alcohol consumption } & Yes & $3215(32.89)$ & 693(33.32) & 0.709 \\
\hline & No & $6559(67.11)$ & 1387(66.68) & \\
\hline \multicolumn{5}{|l|}{ Health status } \\
\hline \multirow[t]{2}{*}{ Disability } & No & $8035(82.21)$ & 1815(87.22) & $<0.001$ \\
\hline & Yes & 1739(17.79) & $266(12.78)$ & \\
\hline \multirow[t]{2}{*}{ Chronic disease } & No & $3205(33.14)$ & $615(29.70)$ & 0.002 \\
\hline & Yes & $6467(66.86)$ & 1456(70.30) & \\
\hline
\end{tabular}




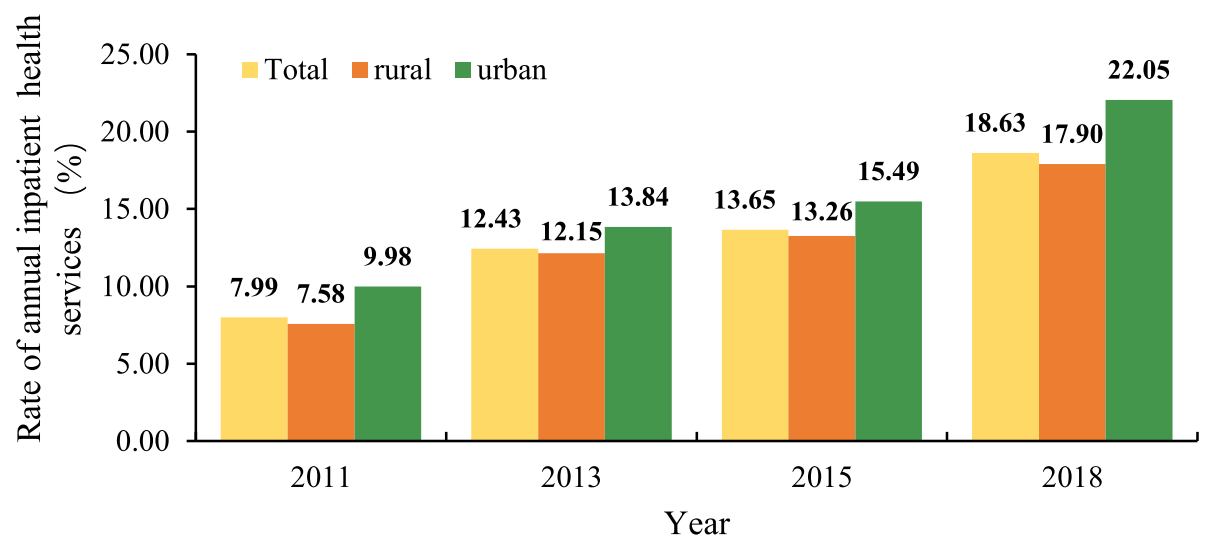

Fig. 2 The rate of annual inpatient health service utilization from 2011 to 2018

receiving IHSU was higher than that of rural respondents. With regard to urban respondents, $9.98 \%$ of respondents received IHSU in 2011; this value slightly increased to $13.84 \%$ in 2013 and $15.49 \%$ in 2015, and more than doubled in 2018 (22.05\%). Compared to 2011, the proportion of rural respondents that received IHSU increased to $17.90 \%$, more than three times the value in 2011 (7.58\%).

A specific, logistic regression showed that the rates of annual IHSU in 2018 were nearly 3.0 times (Odds ratio $(\mathrm{OR})=2.86,95 \%$ confidence limits $(\mathrm{CL}): 2.57,3.19)$ higher for rural respondents and 2.5 times $(\mathrm{OR}=2.49$, 95\%CL:1.99, 3.11) higher for urban respondents than those in 2011 (after adjusting for respondents' sex, age, education, insurance, household income per capita, living status, sleeping hours, smoking status, alcohol consumption, and having a disability or chronic disease, Table 2). Urban and rural respondents with a higher age, no drinking, disability, and chronic disease had higher rates of annual IHSU after adjusting for other characteristics $(p<0.05$; Table 2$)$.

\section{Tendency of equity in IHSU}

Figure 3 shows that, from 2011 to 2018, concentration curves for both urban and rural respondents lay above the line of equality, indicating that the utilization of IHSU was more concentrated among the low-economic respondents. In total, the $\mathrm{CI}$ for receiving IHSU remained negative and increased significantly from 0.2000 to -0.4459 . For rural respondents, this increasing trend was shown from 2011 to 2018; specifically, the adjusted CI was -0.4240 in 2011, and -0.7512 in 2018. For urban respondents, the adjusted CI was decreased from - 0.3016 in 2011 to -0.1536 in 2018 (Table 3).

Table 4 presents the detailed information on elasticity, contributions of each determinant to $\mathrm{CI}$ and pure percentage contributions of each determinants. A positive elasticity, such as health status indicated having chronic disease was significantly associated with the occurring of IHSU, whilst a negative elasticity, such as living alone, decreased the occurring of IHSU. A positive (negative) contribution denotes that the variable raised (reduced) the pro-rich inequality. We found that age, high economic status, and having a chronic disease had the largest $(21.06 \%)$, second largest (17.39\%), and third largest (9.77\%) contributions, respectively, to the inequality of IHSU in 2018. In addition, we found lifestyle had positive elasticity and contributed $17.39 \%$ to the inequality of IHSU. Among lifestyle variables, non-smoking and non-alcohol consumption contributed 3.31 and 4.99\% respectively to inequality in the 2018 IHSU. In total, the HI of IHSU was positive in 2011 (0.0138) but became negative from 2013 to 2018 (2013:-0.0327; 2015:-0.0401; 2018:-0.0514), the adjusted HI kept the same tendency from 2011 to 2018, evidencing a pro-poor inequity.

\section{Discussion}

This study updates the knowledge on the trends in equity of IHSU for the middle-aged and elderly in China in two ways. First, we used large nationally representative longitudinal survey data in CHARLS to evaluate the level of health utilization from 2011 to 2018; thus, the findings are more generalizable to a wider population in China and might help suggest a more convincing trend of IHSU. Second, this study conducted detailed decomposition analysis of the concentration index for respondents' IHSU from 2011 to 2018, facilitating the identification of an effective way to reduce the inequity.

According to the National Health Service survey of China in 2008 and 2013, the IHSU rate of the whole population increased from 6.8 to $9.0 \%$, showing a gradually enhancing trend $[17,18]$. In the present study, we did observe that the level of IHSU among the middleaged and elderly in China increased from 2011 to 2018. This phenomenon is consistent with our hypothesis and is also consistent with the other studies among the 
Table 2 Determinants of inpatient health services utilization by logistic regression $(n=11,912)$

\begin{tabular}{|c|c|c|c|c|c|c|c|}
\hline \multirow[t]{3}{*}{ Variables } & \multirow[t]{3}{*}{ Group } & \multicolumn{3}{|c|}{ Rural $(n=9808)$} & \multicolumn{3}{|c|}{$\operatorname{Urban}(n=2092)$} \\
\hline & & \multirow[t]{2}{*}{$\overline{O R}$} & \multicolumn{2}{|l|}{$95 \% \mathrm{CL}$} & \multirow[t]{2}{*}{$\overline{O R}$} & \multicolumn{2}{|l|}{$95 \% \mathrm{CL}$} \\
\hline & & & Lower & Upper & & Lower & Upper \\
\hline \multicolumn{8}{|l|}{ Demographics } \\
\hline \multirow[t]{4}{*}{ Time (year) } & 2011 & 1.00 & & & 1.00 & & \\
\hline & 2013 & 1.84 & 1.63 & 2.08 & 1.55 & 1.22 & 1.96 \\
\hline & 2015 & 1.90 & 1.70 & 2.12 & 1.85 & 1.47 & 2.34 \\
\hline & 2018 & 2.86 & 2.57 & 3.19 & 2.49 & 1.99 & 3.11 \\
\hline \multirow[t]{2}{*}{ Sex } & Male & 1.00 & & & 1.00 & & \\
\hline & Female & 0.94 & 0.85 & 1.04 & 0.93 & 0.75 & 1.16 \\
\hline \multirow[t]{4}{*}{ Age (years) } & $45-50$ & 1.00 & & & 1.00 & & \\
\hline & $51-60$ & 1.10 & 0.98 & 1.23 & 1.68 & 1.30 & 2.15 \\
\hline & $61-70$ & 1.43 & 1.27 & 1.60 & 2.14 & 1.66 & 2.77 \\
\hline & $\geq 71$ & 1.70 & 1.48 & 1.96 & 3.10 & 2.29 & 4.19 \\
\hline \multirow[t]{2}{*}{ Education } & $\leq$ Elementary school & 1.00 & & & 1.00 & & \\
\hline & $\geq$ Middle school & 1.00 & 0.89 & 1.11 & 1.02 & 0.87 & 1.21 \\
\hline \multirow[t]{2}{*}{ Insurance } & No & 1.00 & & & 1.00 & & \\
\hline & Yes & 1.13 & 0.99 & 1.30 & 1.20 & 0.96 & 1.51 \\
\hline \multirow[t]{3}{*}{ Household income per capita (CNY) } & Low & 1.00 & & & 1.00 & & \\
\hline & Medium & 0.92 & 0.83 & 1.01 & 1.18 & 0.92 & 1.51 \\
\hline & High & 0.75 & 0.66 & 0.85 & 1.08 & 0.85 & 1.37 \\
\hline \multicolumn{8}{|l|}{ Life style } \\
\hline \multirow[t]{2}{*}{ Living status } & Live with others & 1.00 & & & 1.00 & & \\
\hline & Live alone & 1.03 & 0.93 & 1.14 & 0.76 & 0.59 & 0.98 \\
\hline \multirow[t]{3}{*}{ Sleeping hours } & $7-8 h$ & 1.00 & & & 1.00 & & \\
\hline & $\leq 6 \mathrm{~h}$ & 1.14 & 1.06 & 1.24 & 1.17 & 0.99 & 1.37 \\
\hline & $>8 \mathrm{~h}$ & 0.96 & 0.86 & 1.08 & 1.07 & 0.82 & 1.40 \\
\hline \multirow[t]{2}{*}{ Smoking status } & Yes & 1.00 & & & 1.00 & & \\
\hline & No & 1.11 & 1.01 & 1.21 & 0.95 & 0.77 & 1.18 \\
\hline \multirow[t]{2}{*}{ Alcohol consumption } & Yes & 1.00 & & & 1.00 & & \\
\hline & No & 1.18 & 1.07 & 1.29 & 1.26 & 1.04 & 1.52 \\
\hline \multicolumn{8}{|l|}{ Health status } \\
\hline \multirow[t]{2}{*}{ Disability } & No & 1.00 & & & 1.00 & & \\
\hline & Yes & 1.05 & 0.96 & 1.15 & 1.16 & 0.94 & 1.42 \\
\hline \multirow[t]{2}{*}{ Chronic disease } & No & 1.00 & & & 1.00 & & \\
\hline & Yes & 1.93 & 1.77 & 2.11 & 1.80 & 1.48 & 2.19 \\
\hline
\end{tabular}

elderly in China [16, 29]. The medical security system is known to have a positive impact on IHSU; accordingly, the increasing rate of IHSU may be related to the massive increase in demand for medical care following the introduction of medical security systems [30, 31].

The horizontal inequity index changed from 0.0138 in 2011 to -0.0514 in 2018 , suggesting a pro-poor inequity in IHSU, whereby respondents with a low economic status had more IHSU than their high-economic counterparts over the past 10 years. Many studies have confirmed that some demographic or socioeconomic determinants will affect people's use of inpatient services [32-34]. In our study, age, chronic diseases, economic status and lifestyle were found to be associated with the IHSU, conforming to previous study analyzing health inequity [29]. First of all, age and chronic diseases had positive elasticity and pure percentage contribution to $\mathrm{CI}$, which indicated older and having chronic diseases were significantly associated with the occurring of IHSU. This is not difficult to understand because, as people 

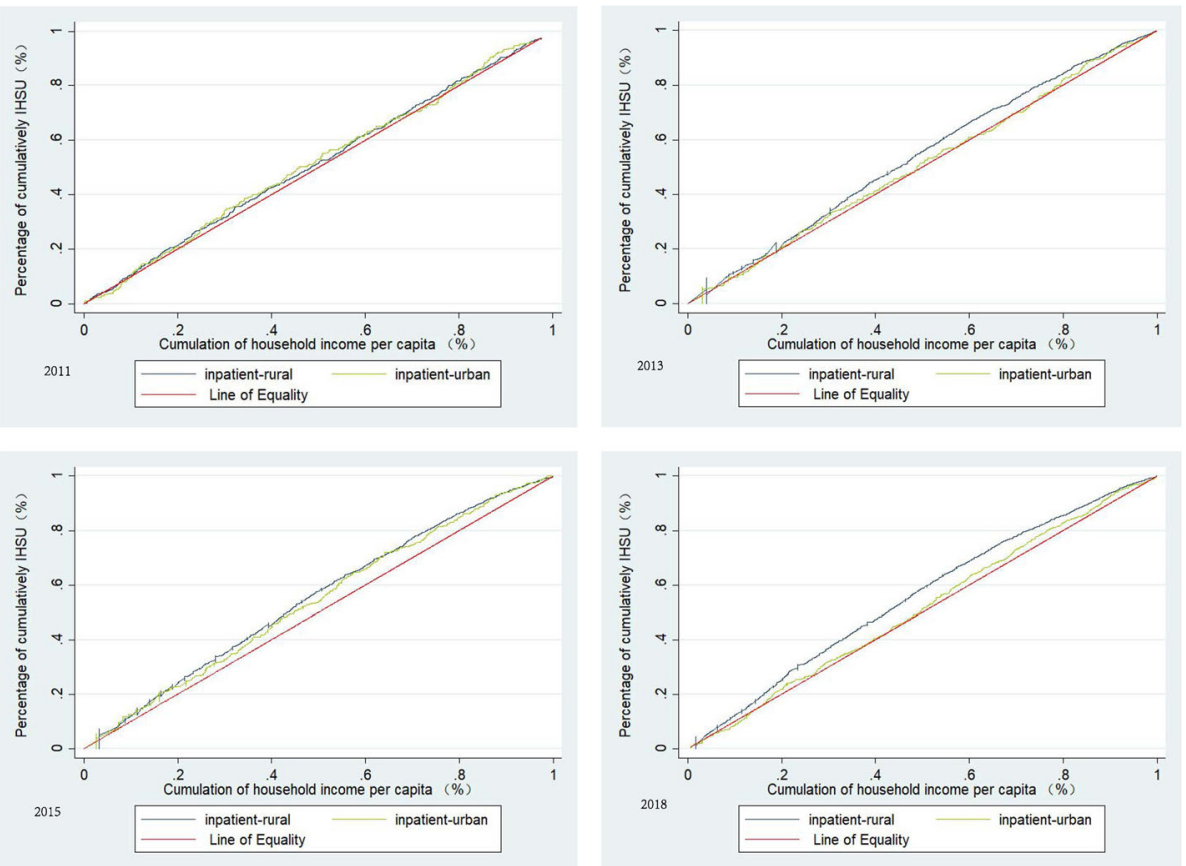

Fig. 3 Concentration curves on inpatient health service utilization from 2011 to 2018

age, their physical functions decline and they require more health services, especially when it comes to the more vulnerable older segment of the population. According to the fifth National Health Service Survey in China, the prevalence of chronic diseases is increasing year by year, with the majority of the population aged 55 and above [35]. Therefore, the elderly with chronic diseases needs more inpatient services. In addition, our basic health insurance reimburses a greater percent-age of inpatient health services, which may lead older people to use inpatient health services for the treatment of chronic diseases.

Secondly, in addition to the contribution of these need variables, we found the economic status had positive elasticity and pure percentage contribution to CI, it contributed $17.39 \%$ to the inequality of IHSU in 2018, which is consistent with previous studies [2, 3, 36]. People with better economic status were more likely to use inpatient health services. One possible explanation is that middle- aged and elderly in better economic situations may have higher expectations for their health and spend more money to obtain higher quality inpatient care. Therefore, health policymakers should consider the key factors that affect equity when allocating health care resources, services, and developing related interventions to meet the diverse health needs of different older population.

Thirdly, among lifestyle variables, we found nonsmoking middle-aged and elderly people of lower economic status have more contribution to inequitable outcome for the poor, they use more IHSU. One explanation might be the health problems that led the middleaged and elderly people to quit smoking, to long-term use of health services thereafter, because previous studies found the former smokers have higher probability of treatments and hospitalization, rehabilitation and the use of medications [37]. Therefore, policy makers need to take into account the health needs of middle-aged and elderly people who have quit smoking in the lower

Table 3 Inequality of annual inpatient health services utilization for respondents from 2011 to 2018

\begin{tabular}{|c|c|c|c|c|c|c|c|c|c|c|c|c|}
\hline \multirow[t]{3}{*}{ Time } & \multicolumn{4}{|c|}{ Total $(n=11,912)$} & \multicolumn{4}{|c|}{ Rural $(n=9808)$} & \multicolumn{4}{|c|}{ Urban $(n=2092)$} \\
\hline & \multirow[t]{2}{*}{$\overline{\mathrm{Cl}}$} & \multicolumn{2}{|l|}{$95 \% \mathrm{CL}$} & \multirow[t]{2}{*}{$\mathrm{Cl}_{\mathrm{a}}$} & \multirow[t]{2}{*}{$\overline{\mathrm{Cl}}$} & \multicolumn{2}{|l|}{$95 \% \mathrm{CL}$} & \multirow[t]{2}{*}{$\mathrm{Cl}_{\mathrm{a}}$} & \multirow[t]{2}{*}{$\overline{\mathrm{Cl}}$} & \multicolumn{2}{|l|}{$95 \% \mathrm{CL}$} & \multirow[t]{2}{*}{$\mathrm{Cl}_{\mathrm{a}}$} \\
\hline & & Lower & Upper & & & Lower & Upper & & & Lower & Upper & \\
\hline 2011 & -0.0147 & -0.0506 & 0.0211 & -0.2000 & -0.0297 & -0.0705 & 0.0107 & -0.4240 & -0.0271 & -0.1043 & 0.0491 & -0.3016 \\
\hline 2013 & -0.0449 & -0.0726 & -0.0173 & -0.4125 & -0.0665 & -0.0975 & -0.0355 & -0.6230 & -0.0124 & -0.0743 & 0.0494 & -0.1040 \\
\hline 2015 & -0.0777 & -0.1040 & -0.0514 & -0.6592 & -0.0927 & -0.1222 & -0.0631 & -0.8060 & -0.0716 & -0.1297 & -0.0134 & -0.5470 \\
\hline 2018 & -0.0676 & -0.0894 & -0.0458 & -0.4459 & -0.1104 & -0.1352 & -0.0855 & -0.7512 & -0.0264 & -0.0730 & 0.0202 & -0.1536 \\
\hline
\end{tabular}

Abbreviations: $\mathrm{Cl}$ Concentration Index; $\mathrm{CL}$ Confidence Limits; $\mathrm{Cl}$ a means the adjusted $\mathrm{Cl}$ 


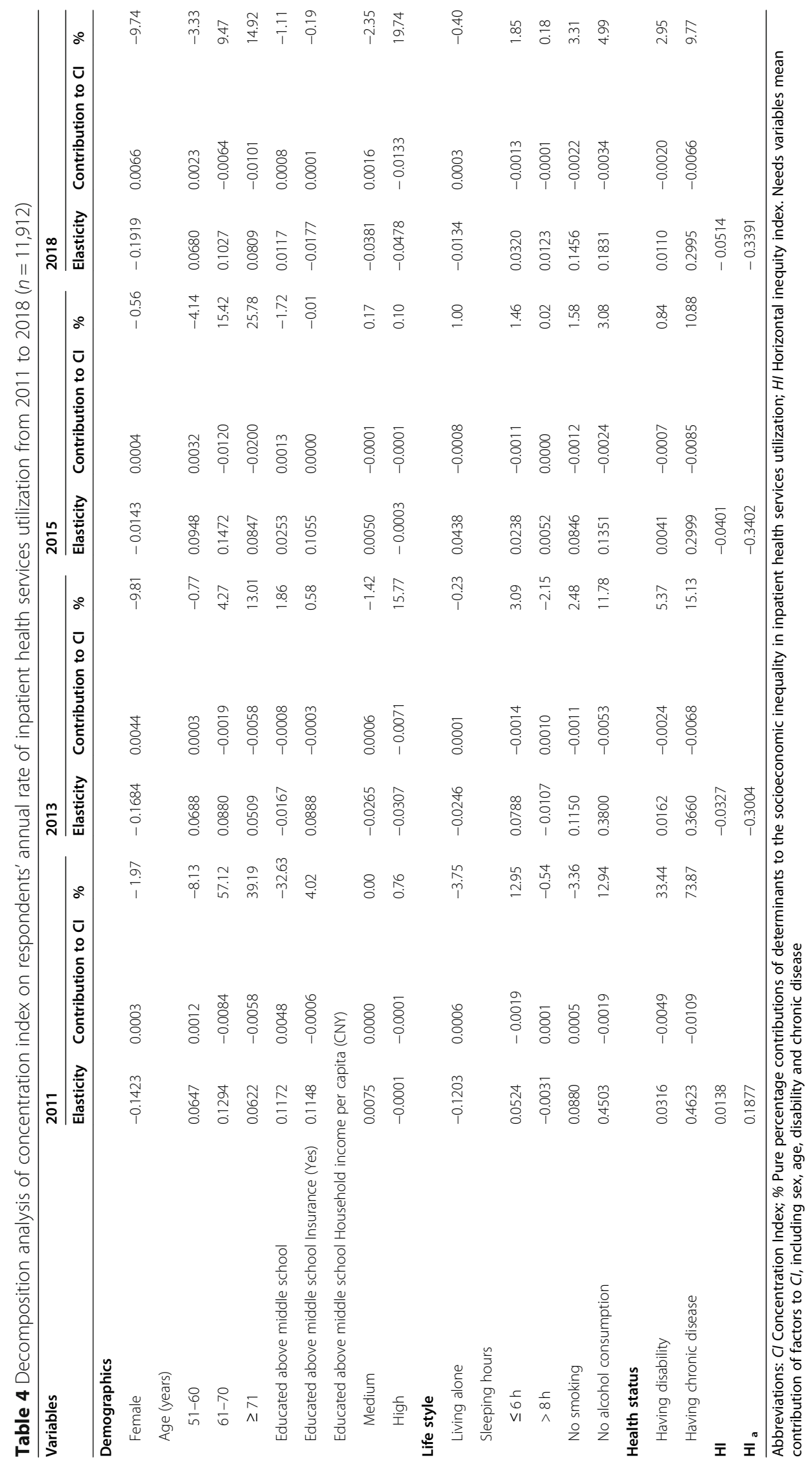


economic levels when formulating future health service related policies. In terms of alcohol consumption, we found non-alcoholic middle-aged and elderly people of lower economic status use more IHSU, which is inconsistent with other researches [38, 39]. Some authors found participants who reduced alcohol consumption to low or completely stop its consumption reported fewer health services utilization [38]. Meanwhile, other authors found no evidence of an association between alcohol consumption and the use of long-term care by older people [39]. More research is needed to explore and verify this association.

This study had several limitations. First of all, all the data were collected via a self-reporting approach and, as such, there may be recall bias. Additionally, the availability of measured determinants of IHSU was limited by the pre-specified questions in the survey, and there could be some potential unobserved confounding factors for which we did not control. Furthermore, although this analysis covered IHSU in 2011, 2013, 2015, and 2018, it was not continuous; hence, the data may not be comprehensive enough to identify the declining level of IHSU and the changes in equity of IHSU. As continuous waves are to be added in the future, it will be important to reexamine these trends.

\section{Conclusions}

The results from this study showed that the urban and rural middle-aged and elderly utilized more inpatient health services over the past 10 years, with greater focus on the lower-economic population. In addition to age > 60 years and having a chronic disease, economic status and lifestyle factors were the main contributors to the pro-low-economic inequity. Health policies to allocate resources and services are needed to satisfy the needs for the middle-aged and elderly, and additional strategies are needed to further reduce the socioeconomic differences in health service utilization.

\section{Abbreviations}

CHARLS: China Health and Retirement Longitudinal Studies; CL: Confidence Limits; Cl: Concentration Index; HI: Horizontal inequity index; IHSU: Inpatient Health Service Utilization; OR: Odds Ratio

\section{Acknowledgements}

We thank the China Health and Retirement Longitudinal Study (CHARLS) team for providing data. We would also like to express our appreciation to all participants in this study for their participation and cooperation.

\section{Authors' contributions}

Conceptualization, M.S., Y.S. and X.F.; methodology, Z.Z., Y.Z. and X.F.; formal analysis, M.S., Y.Z., X.F. and Y.S.; writing-original draft preparation, X.F., M.S., Z.Z. and Y.S.; writing - review and editing, X.F., M.S. and Y.S.; funding acquisition, X.F. and M.S.. All authors reviewed the manuscript. The author(s) read and approved the final manuscript.

\section{Funding}

This research was funded by the National Natural Science Foundation (grant number: 72004178) and Natural Science Foundation of Inner Mongolia (grant number: 2020BS07002).

Availability of data and materials

The datasets and questionnaire are available at http://charls.pku.edu.cn/.

\section{Declarations}

\section{Ethics approval and consent to participate}

Ethical approval for collecting data on human subjects was received at Peking University by their institutional review board (IRB). This approval is updated annually. All subjects gave their informed consent for inclusion before they participated in the survey. We confirm that all methods were carried out in accordance with relevant guidelines and regulations.

\section{Consent for publication \\ Not Applicable.}

\section{Competing interests}

The authors declare that they have no competing interests.

\section{Author details}

${ }^{1}$ School of Public Policy and Administration, Xi'an Jiaotong University, Xi'an, China. ${ }^{2}$ School of Public Administration, Inner Mongolia University, Hohhot, China. ${ }^{3}$ School of Public Health, Xi'an Jiaotong University Health Science Centre, Xi'an, China. ${ }^{4}$ School of Risk \& Actuarial Studies and CEPAR, University of New South Wales, Kensington, Australia.

Received: 29 January 2021 Accepted: 31 May 2021

Published online: 16 June 2021

\section{References}

1. Takahashi S, Jang SN, Kino S, Kawachi I. Gender inequalities in poor selfrated health: cross-national comparison of South Korea and Japan. Soc Sci Med. 2020;255:113028. https://doi.org/10.1016/j.socscimed.2020.113028.

2. Zhu DW, Guo N, Wang J, Nicholas S, Chen L. Socioeconomic inequalities of outpatient and inpatient service utilization in China: personal and regional perspectives. Int J Equity Health. 2017;16(1):210. https://doi.org/10.1186/s12 939-017-0706-8

3. Zhou ZL, Gao JM, Fox A, Rao KQ, Xu K, Xu L, et al. Measuring the equity of inpatient utilization in Chinese rural areas. BMC Health Serv Res. 2011;11(1). https://doi.org/10.1186/1472-6963-11-201.

4. Wiens KE, Lindstedt PA, Blacker BF, Johnson KB, Baumann MM, Schaeffer LE, et al. Mapping geographical inequalities in oral rehydration therapy coverage in low-income and middle-income countries, 2000-17. Lancet Glob Health. 2020;8(8):1038-60.

5. Kachi $Y$, Inoue M, Nishikitani M, Tsurugano S, Yano E. Determinants of changes in income-related health inequalities among working-age adults in Japan, 1986-2007: Time-trend study. Soc Sci Med. 2013;81:94-101.

6. Mukong AK, Van Walbeek C, Ross H. Lifestyle and income-related inequality in health in South Africa. Int J Equity Health. 2017;16(1):103. https://doi.org/1 0.1186/s12939-017-0598-7.

7. Kazemi-Galougahi MH, Mansouri A, Akbarpour S, Bakhtiyari M, Sartipi M, Moradzadeh R. Income-related inequality in completed suicide across the provinces of Iran. Epidemiol Health. 2018;40. https://doi.org/10.4178/epih.e2 018012

8. Mulyanto J, Kringos DS, Kunst AE. The evolution of income-related inequalities in healthcare utilisation in Indonesia, 1993-2014. PLoS One. 2019;14(6):e0218519.

9. Wagstaff A, Van Doorslaer E. Measuring and testing for inequity in the delivery of health care. J Hum Resour. 2000;35(4):716-33. https://doi.org/1 $0.2307 / 146369$.

10. Lofqvist T, Burstrom B, Walander A, Ljung R. Inequalities in avoidable hospitalisation by area income and the role of individual characteristics: a population-based register study in Stockholm County, Sweden. Bmj Qual Saf. 2014:23(3):206-14. https://doi.org/10.1136/bmjqs-2012-001715.

11. Yip W, Fu H, Chen AT, Zhai T, Jian W, Xu R, et al. 10 years of healthcare reform in China: progress and gaps in universal health coverage. Lancet. 2019;394(10204):1192-204. https://doi.org/10.1016/S0140-6736(19)32136-1. 
12. Wang L, Wang Z, Ma Q, Fang G. Yang JA-Ohoo: the development and reform of public health in China from 1949 to 2019. Glob Health. 2019; 15(1):45. https://doi.org/10.1186/s12992-12019-10486-12996.

13. Meng Q, Mills A, Wang L, Han Q: What can we learn from China's health system reform? BMJ 2019;365:12349. doi: 23https://doi.org/10.113 6/bmj.12349.

14. Opinions on deepening health system reform. Zhongfa 2009 No. 6. 2009. [http://www.china.org.cn/government/scio-press-conferences/2009-04/09/ content_17575378.htm].

15. Yip WCM, Hsiao WC, Chen W, Hu SL, Ma J, Maynard A. Early appraisal of China's huge and complex healthcare reforms. Lancet. 2012;379(9818):83342. https://doi.org/10.1016/S0140-6736(11)61880-1.

16. Sun J, Lyu XY, Yang F. The effect of new rural cooperative medical scheme on the socioeconomic inequality in inpatient service utilization among the elderly in China. Risk Manag Healthc P. 2020;13:1383-90. https://doi.org/1 $0.2147 /$ RMHP.S252336

17. Council NH. China health statistics yearbook. Beijing: China Union Medical University Press; 2018.

18. An analysis report of national health services survey in China [https://wenku baidu.com/view/524bb5ebf8c75fbfc77db258.html]. Accessed 07 Apr 2012.

19. Zhao Y, Hu Y, Smith JP, Strauss J, Yang G. Cohort profile: the China health and retirement longitudinal study (CHARLS). Int J Epidemiol. 2014;43(1):618. https://doi.org/10.1093/ije/dys203.

20. Zhao Y, Strauss J, Yang G, Giles J, Hu PP, Hu Y, et al. China health and retirement longitudinal study, 2011-2012 National Baseline Users' guide. National School of Development, Peking University; 2013.

21. Hu HW, Cao Q, Shi ZZ, Lin WX, Jiang HX, Hou YC. Social support and depressive symptom disparity between urban and rural older adults in China. J Affect Disorders. 2018;237:104-11. https://doi.org/10.1016/j.jad.2 018.04.076.

22. Kenea $\mathrm{D}$, Jisha $H$. Urban-rural disparity and determinants of delivery care utilization in Oromia region, Ethiopia: Community-based cross-sectional study. Int J Nurs Pract. 2017;23(1):e12510.

23. Song HX, Feng D, Wang RX, Yang J, Li YQ, Gao JL, et al. The urban-rural disparity in the prevalence and risk factors of hypertension among the elderly in China a cross-sectional study. Peerj. 2019;7:e8015. https://doi.org/1 0.7717 /peerj.8015.

24. You XY, Zhang YL, Zeng JF, Wang CJ, Sun HP, Ma OH, et al. Disparity of the Chinese elderly's health-related quality of life between urban and rural areas: a mediation analysis. BMJ Open. 2019;9(1):e024080

25. Wagstaff A, Paci P, Vandoorslaer E. On the measurement of inequalities in health. Soc Sci Med. 1991;33(5):545-57. https://doi.org/10.1016/02779536(91)90212-U.

26. Wagstaff $A$. The bounds of the concentration index when the variable of interest is binary, with an application to immunization inequality. Health Econ. 2005;14(4):429-32. https://doi.org/10.1002/hec.953.

27. Chang CD. Social determinants of health and health disparities among immigrants and their children. Curr Prob Pediatr Ad. 2019:49(1):23-30.

28. Ascione F, Cascone D, Napolitano F, Di Giuseppe G. Evaluation of the use of health care services for noncommunicable disease and prevention by children and adolescents in South Italy. BMC Health Serv Res. 2017;17(1):532. https://doi.org/10.1186/s12913-017-2489-4

29. Wen XT, Cui LY, Yuan F, Liu XJ, Ouyang MF, Sun YX, et al. Study on the Utilization of Inpatient Services for Middle-Aged and Elderly Rural Females in Less Developed Regions of China. Int J Env Res Pub He. 2020;17(2):514.

30. Fu XZ, Sun N, Xu F, Li J, Tang QX, He JJ, et al. Influencing factors of inequity in health services utilization among the elderly in China. Int J Equity Health. 2018;17(1):144. https://doi.org/10.1186/s12939-018-0861-6.

31. Yang W. China's new cooperative medical scheme and equity in access to health care: evidence from a longitudinal household survey. Int J Equity Health. 2013;12(1):20. https://doi.org/10.1186/1475-9276-12-20.

32. Jankovic J, Simic S, Marinkovic J. Inequalities that hurt: demographic, socioeconomic and health status inequalities in the utilization of health services in Serbia. Eur J Pub Health. 2010;20(4):389-96. https://doi.org/10.1 093/eurpub/ckp189.

33. de Waure C, Bruno S, Furia G, Di Sciullo L, Carovillano S, Specchia ML, et al. Health inequalities: an analysis of hospitalizations with respect to migrant status, gender and geographical area. Bmc Int Health Hum R. 2015;15:2.

34. Zhang CC, Lei XY, Strauss J, Zhao YH. Health insurance and health care among the mid-aged and older Chinese: evidence from the National
Baseline Survey of CHARLS. Health Econ. 2017;26(4):431-49. https://doi.org/1 $0.1002 /$ hec.3322.

35. Jiang L, Yu Q, Yin W, Huang D, Sun K, Yin C. Analysis of change trend of chronic diseases of Chinese residents based on reports of five National Health Service Surveys. Chin Health Serv Manag. 2018;35(11):874-876,880.

36. Su M, Zhou ZL, Si YF, Wei XL, Xu YJ, Fan XJ, et al. Comparing the effects of China's three basic health insurance schemes on the equity of health related quality of life: using the method of coarsened exact matching. Health Qual Life Out. 2018;16(1):41. https://doi.org/10.1186/s12955-018-0868-0.

37. Wacker M, Holle R, Heinrich J, Ladwig KH, Peters A, Leidl R, et al. The association of smoking status with healthcare utilisation, productivity loss and resulting costs: results from the population-based KORA F4 study[J]. BMC Health Serv Res. 2013;13(1):278. https://doi.org/10.1186/14 72-6963-13-278.

38. Trujillo-Olea F, Fernández-Niño JA, Salmerón J, Gallegos-Carrillo K. Prospective patterns of modifiable health risk behaviors and the utilization of healthcare services in the "health workers cohort study" in Mexico[J]. PLoS One. 2018;13(12):e0208172. https://doi.org/10.1371/ journal.pone.0208172.

39. Jahangir E, Irazola V, Rubinstein A. Need, enabling, predisposing, and behavioral determinants of access to preventative care in Argentina: analysis of the national survey of risk factors. PLOS ONE. 2012;7(9):e45053.

\section{Publisher's Note}

Springer Nature remains neutral with regard to jurisdictional claims in published maps and institutional affiliations.

\section{Ready to submit your research? Choose BMC and benefit from:}

- fast, convenient online submission

- thorough peer review by experienced researchers in your field

- rapid publication on acceptance

- support for research data, including large and complex data types

- gold Open Access which fosters wider collaboration and increased citations

- maximum visibility for your research: over $100 \mathrm{M}$ website views per year

At $\mathrm{BMC}$, research is always in progress.

Learn more biomedcentral.com/submissions 